\title{
Doença vestibular periférica decorrente de osteoartropatia temporoió́dea em um eqüino
}

\author{
Peripheral vestibular disease associated with temporohyoid \\ osteoarthropathy in a horse
}

\author{
Alexandre Secorun Borges ${ }^{1}$ José Luiz de Mello Nicoletti $^{2}$ \\ Armen Thomassian ${ }^{3}$ Énio Pedone Bandarra ${ }^{4}$ Ana Laura Angeli ${ }^{5}$
}

\section{-RELATO DE CASO-}

\section{RESUMO}

Um eqüino com 22 anos de idade apresentou sindrome vestibular periférica associada à paralisia de nervo facial esquerdo devido à osteoartropatia temporoioidea. $O$ exame endoscópico das bolsas guturais mostrou alteração de contorno da bula timpânica esquerda e aumento de volume da extremidade proximal do osso estiloióide do mesmo lado.

Palavras-chave: sistema vestibular, nervo facial, endoscopia, bolsa gutural.

\section{ABSTRACT}

A 22-year-old gelding showed vestibular syndrome associated with left facial nerve paralysis due to temporohyoid osteoarthropathy and the diagnostic was confirmed by guttural pouch endoscopic examination. The exam revealed abnormal contour of the left tympanic bulla and an enlargement of the proximal part of the left stylohyoid bone.

Key words: vestibular system, facial nerve, endoscopic examination, guttural pouch.

\section{INTRODUÇÃO}

A osteoartropatia temporoioídea é uma doença progressiva e crônica dos ossos que compõem a articulação temporoioídea - parte proximal do osso estiloióide e parte ventral da porção petrosa do osso temporal (BLYTHE \& WATROUS, 1997). Essa enfermidade pode acarretar anormalidade vestibular, com ocorrência pouco freqüente nos eqüinos quando comparados com outras espécies (JOHNSON\& KELLAM, 2001).

As principais suspeitas etiológicas deste processo são a otite média interna por via hematógena, doença degenerativa articular ou trauma (JOHNSON \& KELLAM, 2001). Na otite média interna, ocorreria inicialmente uma infecção microbiana no ouvido médio, provavelmente por contaminação via hematógena. A infecção acarretaria uma osteíte das estruturas ósseas adjacentes, como a bula timpânica, parte proximal do osso estiloióide e articulação temporoioídea, e essa última

\footnotetext{
${ }^{1}$ Professor Assistente, Doutor, Faculdade de Medicina Veterinária e Zootecnia (FMVZ), Universidade Estadual Paulista (UNESP), Departamento de Clínica Veterinária, Distrito de Rubião Júnior, 18618-000, Botucatu, SP. Brasil. E-mail: asborges@fmvz.unesp.br. Autor para correspondência.

${ }^{2}$ Professor Adjunto, Doutor, FMVZ, UNESP, Botucatu. Departamento de Cirurgia e Anestesiologia Veterinária.

${ }^{3}$ Professor Titular, Doutor, FMVZ, UNESP, Botucatu. Departamento de Cirurgia e Anestesiologia Veterinária.

${ }^{4}$ Professor Adjunto, Doutor. FMVZ, UNESP, Botucatu, Departamento de Clínica Veterinária.

${ }^{5}$ Médica Veterinária, Pós-graduanda, FMVZ, UNESP, Botucatu, Departamento de Cirurgia e Anestesiologia Veterinária.
} 
articula-se com o osso petroso temporal (BLYTHE et al., 1984; BLYTHE et al., 1994; HASSEL et al., 1995; BLYTHE, 1997; NEWTON \& KNOTTENBELT, 1999; MOORE 2000). O diagnóstico etiológico de anormalidades precoce de otite média primária em eqüinos é difícil devido ao longo canal auditivo externo e à dificuldade de visualização da membrana timpânica (BLYTHE et al., 1984).

No estádio inicial da osteoartropatia temporoioídea, os sinais clínicos caracterizam-se por balançar da cabeça e rotação incluindo o pescoço, o animal passa a esfregar a orelha em diversos locais, apresenta relutância na apreensão de alimento, deixando-o cair da boca, e conseqüente perda de peso. Ao exame físico, pode demonstrar dor à palpação das cartilagens na base da orelha e o canal auditivo externo pode ter o seu diâmetro diminuído devido à proliferação óssea. Porém, em alguns casos não há sinais clínicos nesta fase da doença (BLYTHE, 1997; BLYTHE \& WATROUS, 1997).

A segunda fase da doença se caracteriza pelo início agudo dos déficits neurológicos dos nervos facial (VII) e vestibulococlear (VIII). Como sinais de paralisia de nervo facial observam-se paralisia auricular e palpebral no lado afetado, acúmulo de alimento na cavidade bucal, lábio superior desviado para o lado oposto ao da lesão, podendo ainda haver dificuldade em deglutir por envolvimento dos nervos glossofaríngeo e vago. Ocorre também redução na secreção da glândula lacrimal em virtude dos danos na inervação parassimpática, levando à úlcera de córnea (BLYTHE, 1997; BLYTHE \& WATROUS, 1997). Os sinais de comprometimento do VIII par de nervo craniano, são: fraqueza dos músculos extensores no lado afetado resultando em ataxia assimétrica; rotação de cabeça para o lado comprometido e nistagmo espontâneo com fase rápida contrária ao lado lesado (BLYTHE, 1997; JOHNSON et al., 2001). Um histórico completo e exames físico e neurológico são necessários para um acurado diagnóstico nos animais com sinais clínicos de balanço de cabeça, e déficits dos nervos facial e vestibulococlear (BLYTHE, 1997). O tratamento da osteoartropatia temporoioídea tem como objetivos eliminar o processo infeccioso, diminuir a dor e a inflamação. O uso de antimicrobianos sistêmicos durante 30 dias é recomendado, devendose dar preferência para aqueles que penetram no sistema nervoso central. O uso concomitante de antiinflamatórios não esteróides durante a fase inicial do tratamento ajuda a recuperação dos animais (BLYTHE \& WATROUS, 1997).

O objetivo deste trabalho é descrever um eqüino com anormalidade do sistema vestibular decorrente de uma osteoartropatia temporoioídea diagnosticada por exame endoscópico da bolsa gutural, sendo que não foram encontrados relatos na literatura nacional compilada sobre casos semelhantes nesta espécie.

\section{RELATO DO CASO}

Descreve-se o problema em um eqüino, macho castrado, sem raça definida, e com idade aproximada de 22 anos. O mesmo era mantido em piquete em companhia de mais 2 animais. Há cerca de 2 anos, foi submetido à fenestração de bolsa gutural com acesso cirúrgico realizado pelo triângulo de Viborg pelo lado esquerdo.

Apresentou inicio súbito de paralisia de nervo facial caracterizado por ptose do pavilhão auricular, ptose palpebral e flacidez labial (superior e inferior) esquerdas. Após uma semana, apresentou rotação de cabeça para o lado esquerdo. Em seguida, manifestou nistagmo horizontal com fase rápida para o lado direito. Não havia aumento de sensibilidade na palpação do pavilhão auricular nem sinais de secreção no mesmo. O quadro clínico foi acompanhado durante mais 30 dias sendo que durante este período ocorreram momentos em que o nistagmo não estava presente, porém a rotação de cabeça e a paralisia de nervo facial persistiam. Quando submetido ao teste de Romberg, apresentava aumento da área de sustentação (ampla base), desequilibrandose no decorrer da permanênica com os olhos vendados. Ao exame oftálmico, diagnosticou-se úlcera de córnea no olho com ptose palpebral e menor produção lacrimal, constatada pelo teste de Schirmer. Não haviam tremores de intenção nem hipermetria. O nível de consciência estava adequado e, apesar de o animal apresentar tendência de deslocar-se para a esquerda, não havia déficit proprioceptivo. Durante todo o período de acompanhamento, o animal apresentou uma enorme dificuldade de apreensão de alimentos, emagrecendo progressivamente.

O exame endoscópico não evidenciou secreção nas bolsas guturais. Porém, observou-se contorno irregular de bula timpânica articulada com o osso estiloióide esquerdo, tendo este último sua extremidade proximal aumentada de volume.

O exame do líquor obtido por punção atlantooccipital não mostrou anormalidades, estando o número de células nucleadas e de proteína dentro dos valores considerados normais para a espécie. $O$ tratamento não foi realizado devido à avançada idade do animal e a eutanásia foi realizada após 40 dias de evolução, quando o mesmo sofreu queda na baia vindo a apresentar fratura em tuberosidade coxal. Após a eutanásia, foi realizada radiografia post-mortem do crânio em posição dorso- 
ventral e latero-lateral, porém não foi possível a visualização de alterações.

À necropsia, o crânio foi aberto em seu plano mediano, e a bula timpânica esquerda apresentava-se aumentada de volume, como visualizado no exame endoscópico (Figura 1). O corte longitudinal desta estrutura evidenciou uma secreção esbranquiçada e caseosa que, submetida a exame citológico mostrou ser constituída em quase sua totalidade de leucócitos polimorfonucleares (neutrófilos) em diversas fases de degeneração, e presença de hemácias, fragmentos celulares e massa amorfa (secreção purulenta), caracterizando processo inflamatório. A abertura do lado direito não mostrou anormalidades nas estruturas acima citadas.

\section{DISCUSSÃO}

Os sinais clínicos apresentados pelo animal são compatíveis com a paralisia do VII (facial) e VIII (vestibulococlear) pares de nervos cranianos. A úlcera de córnea verificada deve-se, portanto, à perda do reflexo protetor palpebral e à menor produção de lágrimas (GEISER etal., 1988; MOORE, 2000). O animal em questão não apresentava sinais de síndrome de Horner.

$\mathrm{O}$ eqüino estudado apresentou uma síndrome vestibular associada à paralisia do nervo facial, o que está de acordo com GEISER et al.,(1988) e MOORE (2000) que verificaram essa possibilidade em virtude da proximidade com o nervo vestibulococlear dentro do osso petroso temporal. A paralisia associada dos nervos facial e vestibulococlear é considerada rara por POWER et al. (1983), havendo a descrição de poucos casos na

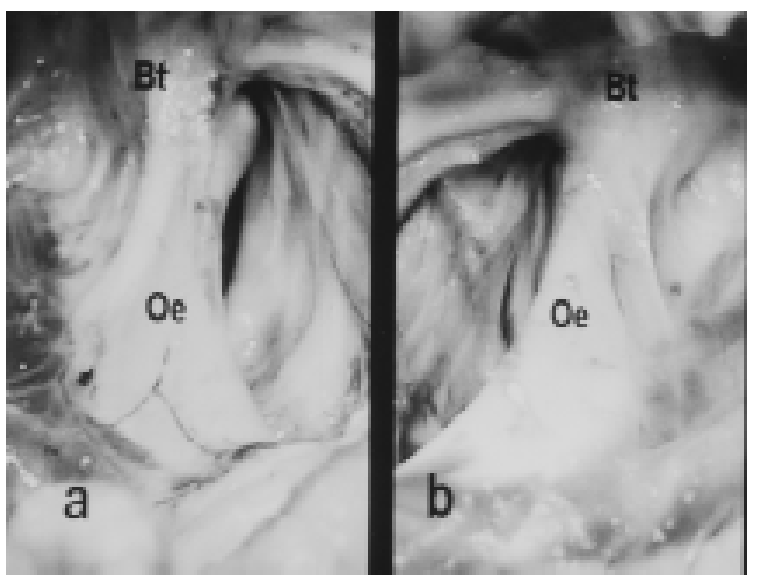

Figura 1 - Osteoartropatia da articulação temporoioídea do lado esquerdo (B) em um equino comparado com o lado normal (A) ao exame de necrópsia; mostrando alteração de contorno de bula timpânica (Bt) esquerda e aumento de volume de extremidade proximal do osso estiloióide (Oe) do mesmo lado. literatura, desta forma destacam-se FIRTH (1977), BLYTHE et al. (1984) e HASSEL et al. (1995) que relatam 3 casos cada um e POWER et al. (1983) com 6 relatos. As síndromes vestibulares podem ser classificadas em periféricas e centrais, como descrevem JOHNSON et al. (2001), e nesse caso, os sinais indicam uma síndrome vestibular periférica pois não ocorreram déficits proprioceptivos nos membros e o nível de consciência estava adequado. O lado afetado era o esquerdo, pois nas síndromes vestibulares periféricas a rotação de cabeça ocorre para o lado da lesão e a fase rápida do nistagmo é contrária à mesma; associada a isto, a paralisia do nervo facial era ipsilateral ao quadro, assim como a diminuição do tônus muscular.

A queda sofrida por esse eqüino, que resultou em fratura de ílio em tuberosidade coxal, provavelmente foi devido a uma combinação de desorientação espacial e inibição de neurotransmissão vestibuloespinhal ipsilateral, que resulta em flexão inadequada dos membros ipsilaterais e extensão dos membros contralaterais (JOHNSON et al., 2001).

Durante o período de acompanhamento não foi verificada febre, secreção ou mesmo sensibilidade à palpação do pavilhão auricular, concordando com os achados de POWER et al. (1983), que não observaram estes sinais em $50 \%$ dos animais por eles avaliados.

A ausência de anormalidade radiográfica deve-se provavelmente à metodologia de posicionamento utilizada, sendo que POWER et al. (1983) ressaltam a necessidade de vários posicionamentos principalmente a posição ventrodorsal, a mais eficiente na identificação de sinais de osteíte da bula timpânica e da porção petrosa do osso temporal, encontrados em alguns dos casos de otite por eles avaliados. Outras lesões radiográficas possíveis de serem encontradas são a proliferação óssea do estiloióide ou a fusão da articulação temporoioídea (BLYTHE \& WATROUS, 1997).

A anormalidade verificada no exame endoscópico da bolsa gutural esquerda confirma a importância deste exame nos animais portadores de síndrome vestibular periférica (BLYTHE \& WATROUS, 1997; NEWTON \& KNOTTENBELT, 1999; MOORE, 2000; JOHNSON \& KELLAM 2001). Neste animal, não foi possível definir a causa inicial de anormalidade nesta articulação, concordando com MOORE (2000) e JOHNSON \& KELLAM (2001), que ressaltam a dificuldade de estabelecer o diagnóstico etiológico deste processo. Devido ao tempo decorrido do procedimento e à imagem endoscópica obtida, em que não se observaram alterações da parede da bolsa gutural, acredita-se 
que o aparecimento desta infecção não tenha sido originado no procedimento realizado anteriormente (fenestração).

\section{CONCLUSÃO}

O presente relato contribui para ressaltar a importância do exame endoscópico das bolsas guturais para avaliar a articulação temporoioídea em eqüinos com síndrome vestibular periférica.

\section{REFERÊNCIASBIBLIOGRÁFICAS}

BLYTHE, L.L. et al. Vestibular syndrome associated with temporohyoid joint fusion and temporal bone fracture in three horses. Journal of American Veterinary Medical Association, v.185, p.775-782, 1984.

BLYTHE, L.L. et al. Prophylactic partial stylohyoidostectomy for horses with osteoarthropathy of the temporohyoid joint. Journal Equine Veterinary Science, v.14, n.1, p.32-37, 1994.

BLYTHE, L.L. Otitis media and interna and temporohyoid osteoarthropathy. Veterinary Clinics North America: Equine Practice; v.13, n.1, p.21-42, 1997

BLYTHE, L. L.; WATROUS, B. J. Temporohyoid osteoarthropathy (Middle ear disease). In: ROBINSON, N.E. Current therapy in equine medicine 4. Philadelphia : Saunders. 1997. Cap.6, p.323325.

FIRTH, E.C. Vestibular disease, and its relationship to facial paralysis in the horse: a clinical study of 7 cases. Australian Veterinary Journal, v.53, p.560-565, 1977.

GEISER, D.R.; HENTON, J.R., HELD, J.P. Tympanic bulla, petrous temporal bone and hyoid apparatus disease in horses. Compendium Continuing Education Practicing Veterinarian, v.10, n.6, p. $740-754,1988$.

HASSEL, D.M. et al. Endoscopy of the auditory tube diverticula in four horses with otitis media/interna. Journal of American Veterinary Medical Association, v.207, n.8, p.1081-1084, 1995.

JOHNSON, P.J.; CONSTANTINESCU, G.M.; FRAPPIER, B.L. The vestibular system. Part I: anatomy, physiology and clinical signs from altered vestibular function. Equine Veterinary Education, v.3, n.2, p.136-140, 2001.

JOHNSON, P.J., KELLAM, L.L. The vestibular system. Part II: Differential diagnosis. Equine Veterinary Education, v.3, n.3, p.185-194, 2001.

MOORE, B.R. Doença vestibular. In: REED, S. M.; BAYLY, W. M. Medicina interna eqüina. Rio de Janeiro : Guanabara Koogan , 2000. Cap. 9.6, p.402-408.

NEWTON, S.A.; KNOTTENBELT, D.C. Vestibular disease in two horses: a case of mycotic otitis media and a case of temporohyoid osteoarthropathy. Veterinary Record, v.145, n.5, p. 142-144, 1999.

POWER, H.T.; WATROUS, B.J.; de LAHUNTA, A. Facial and vestibulocochlear nerve disease in six horses. Journal of American Veterinary Medical Association, v.183, n.10, p.1076-1080, 1983. 